Ast. Soc. Trans. vol. v, p. 1) who first systematically used this method, "with a bold but careful hand". The regular curve which we thus obtain, thus freed from the castal errors of observation, is that in which we endeavour to discover the laws of change and succession.

By this method, thus getting rid at once, in a great measure, of errors of observation, we obtain data which are more true than the individual facts themselves. The philosopher's business is to compare his hypotheses with facts. But if we make the comparison with separate special facts, we are liable to be perplexed or misled, to an unknown amount, by the errors of observation; which may cause the hypothetical and the observed result to agree, or to disagree, when otherwise they would not do so. If, however, we thus take the whole mass of the facts, and remove the errors of actual observation, (Ibid., vol. v, p. 4), by making the curve which expresses the supposed observation regular and smooth, we have the separate facts corrected by their general tendency. We are put in possession, as we have said, of something more true than any fact by itself is.

One of the most admirable examples of the use of this Method of Curves is found in Sir John Herschel's Investigation of the Orbits of Double stars. The author there shows how far inferior the direct observations of the angle of position are, to the observations corrected by a curve in the manner above stated. "This curve once drawn", he says, " must represent, it is evident, the law of variation of the angle of position, "with the time, not only for instants intermediate between the dates of " observations, but even at the moments of observation themselves, much " better than the individual raw observations can possibly (on an average) "do. It is only requisite to try a case or two, to be satisfied that by "substituting the curve for the points, we have made a nearer approach to " nature, and in a great measure eliminated errors of observation." "In "following the graphical process", he adds, "we have a conviction, almost "approaching to moral certainty, that we cannot be greatly misled."

\title{
A LONG-LIVED FAMILY.
}

To the Editor of the Journal of the Institute of Actuaries.

SIR,-The vital history, as annexed, of a family of 11 children is so remarkable that it would seem worthy of insertion in the Journal: the father died in 1845, aged 85, and the mother in 1811 , aged about 45 . I would add that the father, one of the founders of a great life office, was the head of a well-known house now rivalling, in the vigour of its official existence, the longevity of certain of its members.

\begin{tabular}{|c|c|c|c|c|c|c|}
\hline \multirow[b]{2}{*}{1} & \multirow{2}{*}{$\begin{array}{l}\text { Sex } \\
\text { F. }\end{array}$} & \multicolumn{2}{|l|}{ Bom } & \multicolumn{2}{|l|}{ Died } & \multirow{2}{*}{$\frac{\text { Age at Death }}{102 \cdot 1}$} \\
\hline & & 7 Dec. & 1789 & 24 Jan. & 1892 & \\
\hline 2 & F. & 23 Feb. & 1791 & 10 Nov. & 1886 & $95 \cdot 7$ \\
\hline 3 & M. & 28 Mareh & 1792 & 10 Jan. & 1881 & $88 \cdot 8$ \\
\hline 4 & F. & 9 April & 1793 & $10 \mathrm{Aug}$. & 1875 & $82 \cdot 3$ \\
\hline 5 & F. & $16 \mathrm{Feb}$ & 1795 & 27 March & 1891 & $96 \cdot 1$ \\
\hline 6 & M. & 4 Sept. & 1796 & & 1796 & (say) 1 \\
\hline 7 & M. & 20 Nov. & 1798 & 28 Sept. & $184: 1$ & $42 \cdot 9$ \\
\hline 8 & M. & 15 Dec. & 1799 & 8 June & 1869 & $69 \cdot 5$ \\
\hline 9 & M. & $23 \mathrm{Jan}$. & 1801 & 29 Dec. & 1888 & $87 \cdot 9$ \\
\hline 10 & M. & 21 April & 1802 & $3 \mathrm{Feb}$. & 1892 & $89 \cdot 8$ \\
\hline 11 & F. & 27 June & 1806 & 8 May & 1807 & $\cdot 9$ \\
\hline
\end{tabular}


The average age at death was therefore 68.7 ; or, leaving the two who died in infancy out of consideration, 83.9 .

\section{I am, Sir,}

Your obedient Servant,

81 King William Street, E.C.,

C. D. HIGHAM.

27 April 1892. 